\title{
I-C-E Framework: Concepts for Group Dynamics Research in Human-Robot Interaction
}

\author{
Revisiting Theory from Social Psychology on Ingroup Identification (I), Cohesion (C) and \\ Entitativity (E)
}

\author{
Anna M. H. Abrams ${ }^{1}$. Astrid M. Rosenthal-von der Pütten ${ }^{1}$
}

Accepted: 11 March 2020 / Published online: 26 March 2020

(c) The Author(s) 2020

\begin{abstract}
The research community of human-robot interaction relies on theories and phenomena from the social sciences in order to study and validate robotic developments in interaction. These studies mainly concerned one (human) on one (robot) interactions in the past. The present paper shifts the attention to groups and group dynamics and reviews relevant concepts from the social sciences: ingroup identification (I), cohesion (C) and entitativity (E). Ubiquitous robots will be part of larger social settings in the near future. A conceptual framework, the I-C-E framework, is proposed as a theoretical foundation for group (dynamics) research in HRI. Additionally, we present methods and possible measures for these relevant concepts and outline topics for future research.
\end{abstract}

Keywords Human-robot interaction · HRI · Group dynamics · ICE framework · Ingroup identification · Cohesion · Entitativity

\section{Introduction}

The field of human-robot interaction (HRI) has developed over the last 20-30years [73]. Studies in this field often involve a human participant and the robot, as an interaction partner. Considering potential, ubiquitous deployments of embodied robots and their integration in daily future life, the scenario of one human and one robot interacting with each other in isolation will be unrealistic in most of the deployment scenarios. Robots will be co-workers, servants, maybe even companions, and thus, will be integrated in a social network consisting of more than only one human interaction partner, and possibly more than only one robotic partner.

Research in the field of social psychology investigating human groups shows that group-level processes are fundamentally different from individual-level processes. One of

Anna M. H. Abrams

anna.abrams@humtec.rwth-aachen.de

Astrid M. Rosenthal-von der Pütten arvdp@humtec.rwth-aachen.de

1 Chair Individual and Technology, RWTH Aachen University, Aachen, Germany the earliest research in this field was done by Kurt Lewin who is known as the founder of field theory in social sciences [48]. The theory builds upon the assumption that individual behaviour results from personal and environmental factors, and the interaction of both. A group influences an individual's behaviour due to the individual's interaction with other members in a social setting. This is what Lewin called "interactionism". Group phenomena can only be understood when a group as a whole is studied on the group-level and cannot be fully understood by observing individuals, thereby ignoring group influences or social settings [26]. An example of group processes that cannot be explained by individual preconditions is the phenomenon of groupthink which is described as an erroneous process of decision making due to social dynamics in groups. Janis Irvin analyzed failed decision making processes by expert groups, among others the Challenger disaster where security concerns somehow got lost in the decision process which finally led to the tragic decision the spacecraft was ready for flight. His explanation of this erroneous decision making is "a mode of thinking that people engage in when they are deeply involved in a cohesive ingroup, when the members' strivings for unanimity override their motivation to realistically appraise alternative courses 
of action" (1982, as cited by [42]). In other words, groupthink appears in groups that are highly cohesive which leads group members to commit mistakes because agreement is set as the highest goal. The example of groupthink shows why research on a group-level is so important. In consideration of findings from group dynamics research and the likely event of robots playing a part in social settings in the near future, research on robots and groups is necessary. Still, groups that interact with robots or robot groups are seldom studied, although the need for a paradigm shift has been acknowledged $[29,44]$.

\subsection{HRI and Group Research}

Many different fields and subjects of study have emerged that are involved in group research with artificial agents. Most research has addressed technical challenges to enable robots to identify, keep track of and attend to multiple humans in interactions. It has been researched in online studies and in interaction studies how humans perceive and evaluate robot groups and whether humans tend to prefer robots that were marked as ingroup members. In laboratory settings and observational studies in the field, researchers explored how interaction in dyads deviate from interaction in groups involving robots and humans with the goal to derive relevant concepts that need further investigation such as emotional climate, social signal modelling, group norms and so forth. In addition, robots have been used to positively shape interactions between humans.

\subsubsection{Technical Solutions to Handle Multiple Users}

New fields of research in HRI and other disciplines such as computer vision emerged to find technical solutions to perception of and behaviour in multi-agent interactions. For instance, regarding computer vision, a robot has to identify multiple objects of interest [10], e.g., potential interaction partners, decide upon relevant objects [59], and keep track of these relevant objects/people [57]. Scholars from the field of social signals processing come into play when a robot takes on the challenge to recognize and interpret social behaviours shown by the identified interaction partners. Human communication is multi-modal (verbal and nonverbal). 60-65\% of communication is nonverbal [11]. Using diverse mechanisms and nonverbal cues, we are able to structure our conversations, regulate turn taking, establish conversational roles, and convey intentions and emotional states and so forth. Especially communication management (e.g., turntaking, back-channeling) and relational communication [12] are heavily based on nonverbal messages and have been addressed in HRI dyads for years. Hence, research groups now shifted to work on realising attention management, turntaking gaze behaviour and other social gaze behaviour for robots in multi-party interactions (e.g., $[7,62,75])$. Motion in human groups has to be interpreted in real time to anticipate future actions of human group members and synthesize the robots" own motion accordingly [40].

\subsubsection{How Humans Perceive Robot Groups}

Other research groups concentrate on humans' perception of entitativity of robot groups or social effects in minimal group paradigms. In online studies featuring pictures or videos of single and groups of robots, Fraune et al. [30] examined when a quantity of robots is perceived as a group and found that number, type, similar colour and synchronized behaviour lead to higher "groupness" (entitativity) perceptions of the observed robots. Synchronicity in movement and similarity in appearance in a group of robots was found to be perceived more negatively, i.e. threatening [28]. Eyssel and coleagues further investigated the impact of social categorization of social robots on its perception. When a robot is presented as an ingroup member (German participants evaluate robot developed in Germany in contrast to fabricated in Turkey) participants show an ingroup bias evaluating the robot developed in Germany more favourably [24]. Moreover, the ingroup robot was identified to be psychologically closer, warmer and having more mind [24]. Willingsness to interact with an ingroup robot and higher acceptance levels could be shown again in a later study [47]. The social category of robots was also investigated in a study done by Häring et al. [32]. Their results support earlier findings by Eyssel and Kuchenbrandt: the ingroup robot was more positively evaluated and anthropomorphized to a higher extent. Taijfels' minimal group paradigm [67] also shows effect in HRI. Participants who were assigned into a "blue" group together with a robot showed an extent of anthropomorphic inferences about the robot and more positive evaluations compared to participants in the condition where the robot was not in the same group [46]. Similarly, intergroup bias can significantly affect how close humans are approaching an ingroup robot and how much they trust the robot's suggested answers with respect to task difficulty [19]. However, this research on perception of robot groups (online studies) and minimal group paradigms (one robot grouped with one human) has so far not been conducted in group settings that go beyond the dyad.

\subsubsection{Group Dynamics in Human-Robot Groups}

First studies have begun to examine group dynamics in interactions between humans and robots. The research predominantly looked into how group interactions differ from interactions in dyads. For instance, engagement or disengagement with the interaction is expressed differently according to the type of interactions and changes across the group size in HRI [50]. Hence, robots "should have different prediction models and, depending on the number of people around it, 
use the most appropriate" (p. 104). Alves-Oliveira et al. [4] developed a framework to distinguish individual-level and group-level emotional expression in interactions in HRI and introduced the concept of emotional climate to HRI. Observational research of robots interacting with human individuals and groups in the wild showed ample indicators of how the constellation of different groups encountered by a robot shapes interactions - often with the result that the robot was unequipped to handle the situation efficiently and socially adequate $[29,64]$. Moreover, researchers investigated in interaction studies the influence of the size of a robot group, for instance with regard to how well participants could detect those robots which indicate attention toward the human by gaze behaviour [3]. The research team of Malte Jung investigated how a robot might positively intervene in interactions between two or more humans to moderate working team conflicts [54] or conflicts between children competing for toys [65] or to shape conversational dynamics for equal consideration of all group members' inputs in a discussion [68].

\subsection{What is a Group?}

Considering the described studies from the field of HRI, some researchers have already begun to study groups involving humans and robots. In order to study phenomena that define groups, a definition of the term "group" itself is essential. A group is commonly described as an assembly of two or more individuals, where two individuals are referred to as a dyad and three as a triad. Larger groups, namely mobs, crowds and other collectives classify as groups as well [66]. A dyad is a very special form of group and will be discarded in the present paper for two main reasons:

- There is a considerable amount of doubt whether dyads are in fact groups. Dyads can be very intimate and unique groups and thus belong to their own category for research [51].

- Dyadic interactions have been primarily studied in the HRI community [29] and the present paper is supposed to shift the attention from only dyadic interactions to triadic and more.

Consequently, groups are defined as an assembly of three or more agents. In this definition, agents can be human or robotic.

Human groups are described and defined by concepts such as entitativity and cohesion. These concepts have been studied extensively in social psychology. In general, the field of HRI is in need of well-studied and validated sociological and psychological phenomena and concepts to work with. As Irfan and colleagues describe, many researchers in this field are engineers who begin with building and designing a robot. When it comes to testing the robot in a study, some researchers are confronted with their lack of training and experience in fundamental theories of the social sciences and empirical methodology [41]. Especially, for non-social scientists a common framework from the social sciences can be a valuable tool. However, for sociologists and psychologists working in the field, a common framework is equally necessary. This is not only the case because the replication crisis has put much doubt on the validity of research results in the social sciences [41] but because some fundamental theories on groups from the 1950s or 1960s have become fuzzy over time. Many times, social psychologists have used entitativity and cohesion interchangeably or cohesion was used to define what entitativity is [69]. As was to be expected, this fuzziness has entered research on groups in the context of HRI, because researchers rely on social psychology research. Scholars in HRI have used the words 'cohesive' and 'unified entity' to give a definition for entitativity [22] and state "entitativity is defined as cohesiveness [...]" [29]. In order to sharply distinguish both concepts, literature from the beginnings of the conceptualization of cohesion and entitativity is reviewed in the present paper. Furthermore, the concept of ingroup identification is integrated in the model as it has been identified as a highly relevant concept for new groups [71]. As groups of robots and multi-agent groups (human-robot groups) are still very uncommon in society, the concept of ingroup identification will be reviewed here.

In this paper, we focus on groups in general and include special forms of groups, such as teams. Teams are called "hyper-groups" [26] because they have the same basic qualities as any group but usually more intense. Teams develop over time, usually have high cohesion, shared action and behaviours related to tasks [60]. Thus, the explained concepts in this paper apply to any group, including teams. However, teams are not synonymous to groups.

\subsection{Objectives}

The present paper provides a brief overview of three very relevant concepts in group research: entitativity, cohesion and ingroup identification. Subsequently, a theoretical framework integrating all concepts based on theories from sociology and psychology is presented that gives an overview on their relation and differentiation. Social psychology is largely influenced by psychological and sociological theories. Roughly, these two areas can be differentiated by the focus and perspective of research: while psychologists are largely interested in intra- and interindividual phenomena, sociologists are concerned with a societal perspective. In group dynamics research, both perspectives together deliver a holistic understanding and are of equal importance. Influencing theories in the field of group dynamics stem from both areas. In the present paper and the presented framework, the two perspectives are considered through the different levels 
in which the three concepts entitativity, cohesion and ingroup identification are located: the group-level and the individuallevel.

However, understanding a theoretical concept does not necessarily mean one knows when and how to measure it. In the last section of this paper, we discuss from which perspectives the concepts can be assessed and which methods are adequate to measure the concept, because a clearly differentiated theoretical underpinning and well-planned operationalization of studied constructs are of great importance for the HRI community.

\section{Reviewing Entitativity: A Group-Level Factor}

Entitativity, meaning the perception of social groups, is seen as a fundamental antecedent of many phenomena studied in social psychology [63]. The term entitativity was coined by Campbell who proposed to apply empirical evidence from visual perception of physical entities to the perception of social groups [13]. Influenced by Gestalt principles such as proximity (elements that are close to each other are grouped together), similarity (elements that are alike are seen as belonging together), common fate (elements moving in the same direction form an entity) and good continuation (elements forming patterns are grouped together), Campbell described the perception of belongingness and their boundaries of social groups as entities. Entitativity is the degree of having the nature of an entity [13]. Still, 40 years later, the concept of entitativity seems to be based upon Campbell's proposal. In three studies, Lickel et al. [53] examined factors that differentiate groups from one another and those factors' relation to the perception of the groups' entitativities. They give the example of an ethnic group and a family that differ in terms of group size, the number of interactions among group members and many other factors (e.g. group size: ethnic group is large, family group is small). In their article, they attempt to find a common framework for studying groups and show that groups are perceived differently concerning their entitativity or "groupness". Variables such as perceived interaction (e.g. amount and intensity of interactions between group members), common goals (e.g. all members of a sports team want to win a game), common outcomes (e.g. a working team presents their solution for a problem), similarity of group members (e.g., similarity in appearance: same hair color or skin tone, same clothing style, wearing uniforms, speaking the same language) and importance of the group are strongly correlated with entitativity. Moreover, group size, duration (e.g. long-lasting group like family or incidental group such as a group of people waiting for the bus) and permeability (e.g. a family is hard to get into vs. you are easily a new member of the group waiting for the bus) are correlated to a weaker extent with perceived entitativity [53]. They tried to answer the question of when a conglomerate of individuals were actually seen as a group, an entity, and when they were simply seen as individuals. Conducting a cluster analysis on participants' perceptions of the Gestalt principles mentioned above, they identified four categories of entitativity: intimacy groups, task groups, loose associations and social categories. In their experiments they let participants indicate how they would rate different conglomerates of people from "not at all a group" to "very much a group". In total, 16 different conglomerates were rated using the VAS. Results showed, that loose associations such as a waiting line at a bank or people at bus stops were seen on the lower end of the concept of "groupness" while intimacy groups such as families and task groups with strong common goals such as sports groups were sorted to the upper end. Medium scale ratings were given to social categories such as "women" and other task groups such as "work teams".

Ip studied the influence of Gestalt principles on perceived entitativity of groups [39]. In their studies they used cartoon aliens to exemplify different constellations. Different from the previously described study by Lickel et al. [53], here, the focus was on finding out which specific cues led participants to see a group as entitative [39]. Thus, participants were given different information on the cartoon aliens, e.g. a group of aliens that was physically similar or that moved synchronously. They found: similar ratings of entitativity resulted from different information. Furthermore, the authors describe the mediating role of perceived common traits for the perception of entitativity when physical similarity was the cue. In addition, the perception of common goals mediated the relationship between synchronous movement and the rating of entitativity [39]. A rather complex relational model of cues is the result of this research. The main finding, however, is that the extent of entitativity was rather independent of the cue given: the ratings were similarly high or low. These findings are consistent with a theory of the formation of perceived entitativity. The theory postulated that a group can be perceived as entitative resulting from two distinct ways: through a categorical construal and a dynamic construal. Depending upon the information an observer has, he or she base their perception upon either categories or dynamics. Both, perceived similarity of group members (a categorical construal) and perceived interaction (a dynamic construal) were found to be antecedents of entitativity [63]. The reported findings suggest that entitativity does not depend on a single cue or factor, but is rather based upon many cues independently, or a combination of them [69].

In general, the more diverse a group's members are perceived and the bigger the group is, the less entitative it is perceived [56]. Does this statement hold true in any case? Are diversity and size of a group negatively correlated to entitativity? Rutchick et al. [63] theorize that, on the one hand, an 
entitative group that is defined by its category is perceived as sharing common traits that are long-lasting. On the other hand, dynamic groups can be diverse and be perceived as entitative as long as they share agency characteristics, for instance, behavioural tendencies.

When reviewing entitativity research, it becomes apparent that entitativity is operationalized by subjective observer ratings and should in consequence be called "perceived entitativity". In consideration of the fundamental beginnings of conceptualizing entitativity, meaning its origin in Gestalt principles, the observer perspective seems inherent to the concept of entitativity. Furthermore, as an external observer only perceives the group as a whole, the description of groupness is based on the group level, rather than on an individual level. An observer is unable to infer how strongly related the group really is and how strongly related each individual feels towards other members of the group.

To conclude, the concept of entitativity defines the perceived groupness of a social unity from an outsider's perspective. For an assessment of entitativity, outside observers rate the unity of a group. The concept exists on the grouplevel only.

\section{Reviewing Cohesion: A Group-Level and Individual-Level Factor}

Cohesiveness was first described as the willingness to stick together in a group and stems from research by Kurt Lewin and colleagues [20]. Cohesion was later defined as a set of forces that keep members together: attraction and repulsion [20]. In contrast to entitativity, that describes how a collective is perceived as a unified entity, group cohesiveness is described as the actual degree to which a group is unified and coherent [53]. Additionally, cohesion has been named in the context of small groups and named the most important variable of small groups [8]. Still, there is a considerable amount of unclarity around the term. The above mentioned descriptions and definitions of cohesion do not indicate whether cohesion depends on factors on the individual level, such as a member's attraction to the group, or on the group level, such as the presence of other groups [69].

In 1950, Festinger and his students Schachter and Back studied cohesion of two housing units at MIT [25]. They defined cohesion as "the total field of forces which act on members to remain in the group" (p. 37) and distinguished between attractiveness of the group and group goals. Dion describes this definition as the beginnings of the differentiation of social and task cohesion [20]. From their studies, Festinger et al. [25] concluded that the higher the group's cohesion, the less deviating behavior was shown. A review of the conceptualization of cohesion from field of forces to a multidimensional construct was done by Dion in 2000 [20].

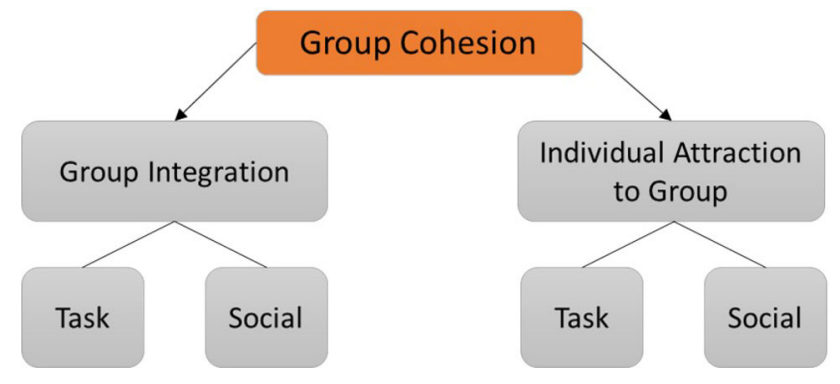

Fig. 1 Carron's hierarchical model of group research [15]

Dion explains that Festinger and colleagues distinguished between the housing units and subgroups, e.g. closer friendships, and set standards for further group research [20]: there is not only one kind of group, groups have different qualities.

Many studies between the 1940s and 1970s involve factor analyses disentangling individual and group variables (e.g. [18]). With the use of factor analyses, researchers started to view cohesion as a multidimensional concept. An influential model stems from research conducted in the field of sports psychology where group processes play an important role. This model integrated the multidimensional view of cohesion [20]:

Carron [15] developed a model and an instrument to assess cohesion, the group environment questionnaire (GEQ). Carron et al. [14] defined cohesion as a twofold construct: on the individual level and on the group level. The individual level involves a member's perception and evaluation, e.g. attraction towards the group (see Fig 1). The group level includes factors such as team members' perceptions of similarity within the group and closeness to the whole group. In a factor analysis, the concept of cohesion with its two levels was further researched and found to consist of two more dimensions besides the individual and group differentiation. The following sub-scales are thus reflected in the GEQ [14]:

- Group integration-task (GI-T): individual group member's perception about similarity and closeness with regard to the task at hand; e.g. Our team is united in trying to reach its goals for performance.

- Group integration-social (GI-S): individual group member's perceptions about group's similarity, closeness and bonding concerning its status as a social unit; e.g. Our team would like to spend time together in the off season.

- Individual attraction to group-task (ATG-T): individual group member's feelings about personal involvement in the group task, the group's goals and objectives; e.g. I'm not happy with the playing time I get (reverse scored). 
- Individual attraction to group-social (ATG-S): individual group member's feelings about personal involvement and acceptance in the group's social activities; For me, this team is one of the most important social groups to which I belong.

In the present paper, this twofold level approach is adopted for all concepts and integrated in the below described conceptual framework: group-level and individual-level. Much of the research on cohesion was conducted with groups such as sports teams, therapy groups [69], and in the military [20]. Hence, research on cohesion normally involves well-established groups. This gives a hint on how cohesion is conceptualized in social psychology. In other words, cohesion is described as resulting from group development processes that lead to an "intense" group [26]. How does a group develop cohesion? The classic group development theory by Bruce Tuckman gives an explanation [70]. Group development comprises 5 different stages: Forming (the orientation stage which consists of self-disclosure and information gathering among the newly formed group's members), storming (a stage dominated by conflicts and a lack of unity), norming (called the structure stage where the group forms norms, roles and cohesion), performing (performance stage) and adjourning (dissolution stage). Especially, the third stage is of importance for cohesion formation according to Tuckman. Establishing norms and rules form a better unity and the group becomes a more intense experience for its members [26]. However, this unanimity of a group can lead to negative consequences such as groupthink [26]. As explained in the introduction part of this paper, groupthink occurs in groups that are highly cohesive and leads to decision-making processes that can have fatal outcomes (cf. Challenger disaster, [42]) On the contrary, cohesion can have positive effects. Cohesion was found to be positively correlated to performance in real groups (not laboratory groups), in correlational studies (not experimental studies) and in small groups rather than in large groups [58]. Does cohesion cause good performance? Forsyth et al. [27] found out that groups that succeed in a task report to feel more cohesive after their performance. After reviewing studies on the cohesion-performance relationship, Forsyth summarizes the relationship is bidirectional: "Cohesion makes groups more successful, but groups that succeed also become more cohesive" (p. 156, [26]).

To sum up, cohesion is a quality that develops in a group and that is measured by asking the group's members to rate the group's groupness on two different levels (individual and group), in two different categories (task and social). It has mostly been researched in the context of established groups (sports teams, therapy groups, work groups, military groups) and in relation to performance.

\section{Reviewing Ingroup Identification: An Individual-Level Factor}

In order to understand how humans start to identify with a group (cf. Sect. 4.3) they are or become a member of, we first have to understand how humans categorize themselves into groups (cf. Sect. 4.1) and why they do so (cf. Sect. 4.2). In the following subsections, first of all, the theories of social identity and self-categorization are explained. Thereafter, ingroup identification is described.

\subsection{How Humans Categorize Themselves Into Groups: Social Identity Theory}

Humans socially categorize themselves and others in order to create a sense of belongingness. Belongingness serves many functions, among others it gives people an idea how to view and treat others [2]. The social identity theory (SIT) by Tajfel and Turner from the late 1970s defines "that part of an individual's self-concept which derives from his knowledge of his membership of a social group (or groups) together with the emotional significance attached to that membership" (Tajfel, 1974, p. 69 as cited by [23]). The theory addresses the borders of individuals thinking in terms of "I" and "We". Very little manipulation is needed for people to feel part of an ingroup which is shown by Tajfel in his minimal group studies. Simply assigning participants to one group or the other leads them allocate more resources to their own group. Later termed the "mere categorization effect", simple verbal categorization of individuals into different groups is sufficient to make people think "we" instead of "I" and behave differently towards the own group and the other [23].

The theory proposes the notion that the group can be found within the individual [17]. However, SIT is not only important to explain individuals' tendencies to categorize themselves and others, but to differentiate groups from one another [26]. Even though SIT provides many explanations for group phenomena, the theory does not give a full answer to the question why people categorize themselves.

\subsection{Why Humans Categorize Themselves Into Groups: Self-Categorization Theory}

The question of why people tended to categorize themselves on a group-level rather than on an individual-level was answered by Abrams and Hogg in the late 1980s: distinguishing successfully between groups enhances self-esteem and a threatened self-esteem benefits from and motivates intergroup bias [1]. As an individual's self-esteem is dependent upon group membership, strategies to protect the group and differentiate it from other groups are important for the individual. In line with these findings, the definition of the self in terms of a group-level factor was proposed by self- 
categorization theory (SCT). SCT distinguishes between different levels of categorization (e. g. someone can selfcategorize as German, as a woman, and as a psychologist) [23].

To sum up, SIT gives an explanation on social categorization of oneself and others which serves to mark off different groups and derive a positive social identity. SCT builds upon SIT and gives an insight in the reason why people engage in social categorization. In the present paper, both (social identity and self categorization) are understood as concepts on the group-level. Social identity and self categorization processes depend on differentiating groups $[1,23,26]$. In order to categorize oneself to one group, one has to create an overview over other groups and be able to distinguish them. This is understood as perspective taking on the group-level.

The beforementioned theories (SIT and SCT) are different from the concept of ingroup identification. An individual might readily self-categorize into a certain group, but that does not necessarily imply a strong identification with that group. Hence, the concept ingroup identification, especially, the process of how someone comes to identify with a certain group, becomes relevant.

\subsection{The Development of Ingroup Identification}

A review on the concept of ingroup identification was done by Leach and colleagues in 2008. They explain five components of ingroup identification that will be reviewed very shortly (cf. [49] for a broader insight):

1. Individual self-stereotyping: the perception of oneself as a group member, the tendency of self-depersonalization and feeling similar to other members

2. ingroup homogeneity: the perception of oneself as an ingroup prototype

3. Satisfaction: positive feelings towards the ingroup

4. Solidarity: the feeling of a personal bond and commitment to the ingroup

5. Centrality: in reference to SCT, the perception of the group as a central aspect of an individual's self

Based on Durkheim's differentiation on mechanical and organic solidarity with groups [21], two factors, on a higher order and more abstract than the five components above, have been found to make up ingroup identification: self-definition and self-investment [49].

- Self-definition is said to be the passive process of selfcategorizing "or the mere inclusion of the self in an ingroup" (p. 428) and is found to be related to selfstereotyping and ingroup homogeneity [61].

- Self-investment is considered to be an active choice for a group and leads to actual investment into the group and thereby related to the other three components (satisfaction, solidarity and centrality).

The multidimensionality of ingroup identification has been tested with the identification to the group of humanity, "the highest level of social abstraction", (p. 426, [61]). The identification with all humanity-(IWAH) scale was developed to measure identification with the "human" ingroup [55]. In three studies, Reese and colleagues found the proposed underlying structure of the two factors. However, mere self-definition as a human was not sufficient to provoke a behavioural outcome. Self-investment indeed proved to be the more active factor, that led people to act (here, donate money) [61].

A lot from SIT and SCT have influenced the conceptualization and understanding of ingroup identification, as shown by Leach's review [49]. How is ingroup identification differentiated? In this article, the differentiation is considered to depend upon on which level we locate the concept.

\subsection{Conceptual Location of Ingroup Identification}

In order to be able to differentiate between categorization processes (from SIT and SCT) and a person's individual identification with a group, ingroup identification is understood as an individual-level variable in the context of our I-C-E framework outlined in this paper. Furthermore, recent findings give an insight in the nature and development of ingroup identification and show us, why the HRI community (human-robot groups) should conceptualize ingroup identification on an individual-level, while social psychology and group dynamics researcher (human groups) shift their view to a multi-level concept.

First, an example: A brown haired person might not identify themselves as much as a brown haired person as a red haired identifies themselves with the group of red haired people. The group of red haired is probably much smaller, thus, more salient, and might even have another status. In Breda, the Netherlands, there is a festival called The Redhead Days where thousands of people with red hair meet annually. The fact that this group has a particular status might be the reason why an individual is prone to feel identified with the group. This would be considered a group-level influence. However, the simple fact that an individual has red hair makes the person eligible to belong to the group of red haired. This rather trivial example shows how group membership depends on individual prerequisites. So, the individual plays a decisive role to which group one belongs to or not. Individual traits were found to be powerful determinants of the occurrence of ingroup identification [9]. Obviously, it can get much more complicated than hair colour. Group belonging becomes more and more complex, the more intra- and 
interpsychological processes play a role in group formation and ingroup identification.

One exemplary group-level influence is the time span a group exists. The longer a group persists, the more the ingroup identification will merge with group-level influences [43]. Considering the duration of existence, unknown and new groups (e.g., human-robot groups) are a special case. Groups that are unknown to the individual are unlikely to influence an individual's decision to join the group [71]. An individual does not know the group, the group's qualities and its individual members. Thus, initial identification processes rely on internal, personal representations of the group and the evaluation of the own individual fit. Through self-anchoring processes, the self is projected onto the group [71] [72]. This stands in utter contrast to SIT and SCT where the group is said to be within the individual. When a group's identity is unclear and undefined, the individual decides, consciously or subconsciously, to identify with one specific group because of an internal belief that group membership will be a good fit. This definition is based on the individual, not on the group.

In this framework proposed for the HRI research community, a clear conceptualization of ingroup identification as a variable on the individual-level is reasonable, since human-robot groups are new and unknown groups to most people. Group dynamics research in psychology and sociology was focused on human interaction. With robots entering the field as possible coworkers, servants and companions, new dynamics will emerge [45]. Considering the findings reported above, robots, as a new group of social agents, and human-robot groups, as unknown conglomerates, will not trigger defined mental representations. Thus, individuals are unlikely to feel identified with robot groups and human-robot groups, because they cannot draw on these mental representations, e.g. knowledge about status. This is the reason why at this point in time, the community of HRI researchers should put an emphasis on the individual-level of ingroup identification. Once interaction increases, individual group members start using the group for self identifying processes [72]. In consequence, once human-robot groups have become known social groups, a shift to a multilevel conceptualization (taking into account the recent findings of dimensions and components of ingroup identification) will be needed.

In conclusion, ingroup identification means projecting oneself onto the group. It depends on individual prerequisites that make an individual eligible to belong to a group. Furthermore, as an individual-level variable, ingroup identification plays a particular role when the group is still unknown to the individual. With passing time and development of a group, ingroup identification cannot be considered an individual-level variable anymore. In the context of HRI, humans encounter unknown and new groups which leads us to consider ingroup identification on the individual-level.

\section{The I-C-E Framework for HRI Research: Ingroup Identification (I), Cohesion (C) and Entitativity (E)}

Drawing on our faceted review of ingroup identification (I), cohesion (C), and entitativity (E), the purpose of our proposed I-C-E Framework as depicted in Fig. 2 is to integrate the concepts and explain their relationship to each other.

We have carved out on which conceptual level the concept should be located - a group level or an individual level. Moreover, we specify whether the consideration of the concepts entail an inside member perspective or an outside observer perspective. In this regard, entitativity is conceptualized as a group-level variable from an outsider/ observer perspective. Cohesion can either be on the group-level or on an individual-level, but necessarily from an inside member perspective. ingroup identification is conceptualized as an individual level variable and can be measured through an inside member perspective. This encompasses methodological consequences regarding how the concepts can be measured (cf. Sect. 6).

All three concepts are correlated. In the following paragraph, relations among the concepts are further explained.

\subsection{Entitativity-Cohesion Relation}

Prior research in human-human interaction (HHI) as well as in HRI, entitativity and cohesion was often used interchangeably. Some researchers even wrote about the concept of "ingroup entitativity" e.g. [17]). Ingroup entitativity would be an ingroup member judgement about the groupness of the group. However, when considering entitativity and cohesion as reviewed above, it is clear that "ingroup" entitativity would in fact be cohesion, because being part of a group, declassifies an individual to be able to be an outside observer. The outside observer perspective is a necessary requirement for the assessment of entitativity. The ingroup member perspective automatically leads an ingroup member to perceive the group's cohesion rather than its entitativity. Even though there is a strong correlation between a group's cohesion and its entitativity, clearly distinguishing these concepts will deliver a more distinct picture of the groupness of groups and sharpen the understanding of group processes.

However, many cue properties have been found to be predictors of both concepts, entitativity and cohesion [69]. For the differentiation of these concepts, these findings pose a challenge. Two studies on the relation of cohesion (task and social) and entitativity delivered high correlations between both concepts. While high correlations are often the case, there might be cases where assuming this correlation will lead to misjudgements. A family might be seen as highly entitative from an outsider perspective, but they may or may not regard themselves as cohesive from an insider perspec- 
Fig. 2 I-C-E Framework for HRI Research

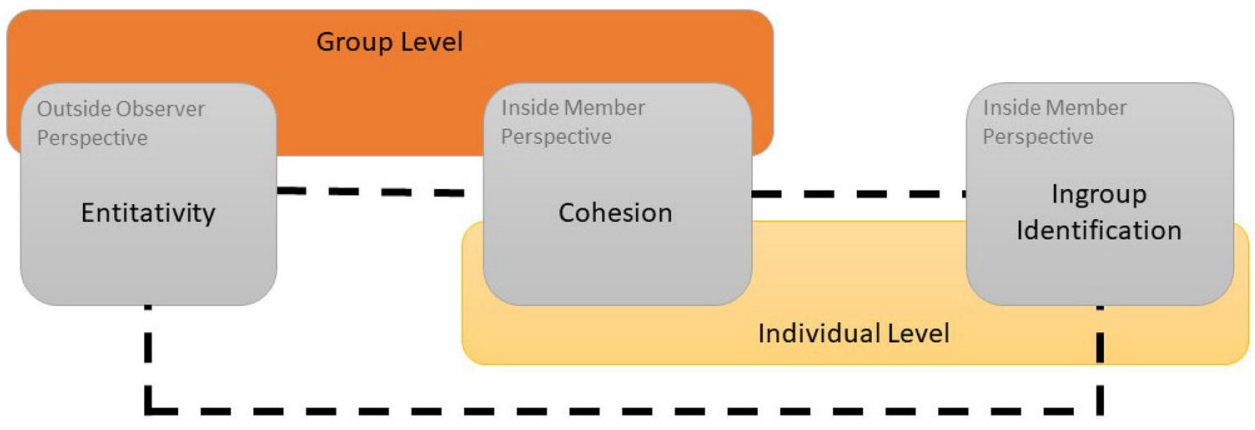

tive. An observer can neither perceive quarrels from the past nor observe a loss of feeling connected. An additional example can be given on a group of convicts standing in line for a bus: They might be perceived as a very entitative group based on their similar appearance in clothing and their shared fate. It is, however, very unlikely that the convicts, who just happen to be on the same bus, regard themselves as a cohesive group.

In order to unravel the concept of cohesion and entitativity, we have to take a closer look into their operationalization. Thurston conducted two studies on cohesion and entitativity and their relationship [69]. In both studies, Thurston examined the entitativity and cohesion of basketball teams. Entitativity was measured by a four-item entitativity scale, entitativity cues (such as interaction between members and shared goals) were assessed by nine items and cohesion was assessed though the 18-item group environment scale (GEQ). In the first study, the questionnaires were given to the players directly after the game. This study delivered highly correlated results of entitativity and task cohesion, and correlations of entitativity and social cohesion to a lesser extent. Here, cohesion and entitativity was assessed by ingroup members. For them, it is impossible to assess how entitative the group is perceived from an observer perspective. In fact, their answers most likely reflected the same concept, namely participants' self-reported cohesion, on both questionnaires. This also means that high correlations are inevitable. In the other study, participants rated 18 basketball teams based on a written description of the teams. Each description reflected one of the nine entitativity cues. The cues were taken from Lickel's eight entitativity cue properties [53], e.g. interaction between members, mutual group importance, shared outcomes and shared goals. One cue was added by Thurston: interpersonal liking among team members. Thurston explains why: it "was added due to the importance that interpersonal liking is typically ascribed in the cohesion literature" (p. 51, [69]). These cue properties were positively correlated with entitativity, task cohesion and social cohesion [69].

In light of the current I-C-E framework, the distinction between both concepts could not be found in the two studies because the perspective of measurement did not reflect the theoretical descriptions of entitativity and cohesion. Both concepts were measured using questionnaires given to a real team and later to a group of observers (lab study participants). High correlations among the concepts, given that many cue properties had been found to predict both concepts alike, are very logical. The same rater from the same perspective evaluated the teams' groupness: first, ingroup members assessed their own ingroup's entitativity and cohesion, second, observers assessed teams' entitativity and cohesion. The internal validity of the assessment of both concepts is questionable. Was it really cohesion and entitativity, two distinct concepts, that were measured? The current framework proposes another understanding and approach: The perspective is the main differentiation between entitativity and cohesion.

While entitativity, due to its measurement perspective (outside observer perspective), can only be measured on the group level, cohesion is more complex. On the one hand, cohesion, measured though evaluation of an ingroup member, can be operationalised as an individual member's attraction to the group, liking, importance, and other factors (inside member perspective, individual-level). On the other hand, cohesion can be an evaluation of the whole group's groupness made by an ingroup member (inside member perspective, group-level). Building upon other research, decade after decade of research, concepts and their assessment had become fuzzy. Researchers studying the concept of cohesion studied solely cohesion and researchers interested in entitativity developed the concept of entitativity.

Conceptualisations of social psychology constructs effect research in HRI as well. In an exploratory study, group effects in interaction were studied with a robot in a public mall in Japan [29]. The robot actively approached humans once they were about one metre away from it and provided explanations for direction. After an interaction, people were approached by researchers and asked to fill in a survey on group size, group type, entitativity, ratings of the robot and some personal information. They found more entitative groups to be more positive toward the robot, to interact more and longer and to behave more socially [29]. However, the measurement of entitativity consisted of self-reports. Additionally, entitativity was defined as "i.e., cohesiveness with group" (p. 5). 
In this study, cohesion rather than entitativity was assessed. The findings from this study should thus be reframed: More cohesive groups are more positive toward the robot, interact more and longer and behave more socially. However, the researchers could have considered to link cohesion with entitativity. By video taping the interactions, researchers could have shown them to participants in a lab and assess entitativity on Likert scales or by rating or sorting them, e.g. similar to Lickel et al. [53] or Ip et al. [39]. Self-reported cohesion and coded entitativity could be correlated.

Two years earlier, the same researchers conducted a study on the effect of entitativity on perceived threat and behavioral aggression towards robots [28]. This study used perceptional observer measurement methods for entitativity [28]. Entitativity was manipulated by a robot's appearance, motion, decision making and proximity. Participants assessed the robots' entitativity from an observer perspective with items such as "This group of robots should be thought of as a whole" (general entitativity), "These robots are affected by behaviors of other members of this group" (dynamic entitativity) and "These robots have similar physical appearances" (static entitativity). They found that entitative groups of robots were seen as more threatening in comparison to a single robot and a group of robots that had been varied in appearance only [28]. In this study, entitativity was assessed with observer's perceptions which corresponds well to the theoretical definition.

The relationship of entitativity and cohesion can be summarized as follows:

- Relation: Many cues (e.g. interaction between members, mutual group importance, shared outcomes and shared goals) have been found to predict cohesion and entitativity.

- Differentiation: Entitativity is a group-level variable and assessed through an outsider's perspective. Cohesion exists on the group-level and on the individual-level and is assessed through an insider's perspective.

When conducting research on either cohesion or entitativity of groups, the methods of gathering data play the most important role. Otherwise, internal validity of entitativity and cohesion is at stake. When reporting results of previous research, we would like to advise others to scrutinize measurement level and perspective in order to clearly distinguish between constructs.

\subsection{Cohesion-Ingroup Identification Relation}

When looking into the literature on ingroup identification and cohesion, one finds out quickly that not only cohesion and entitativity get mistaken and used interchangeably, but the same problem exists for cohesion and ingroup identification [33].

Henry et al. [33] have proposed a model for ingroup identification and try to distinguish it from cohesion. First of all, they explain how they relate: interpersonal attraction, relevant to cohesion, is a source of ingroup identification. The developing bonds between group members heighten both, cohesion and ingroup identification. The difference between both concepts is their relevance and meaning to the group and to the individual. While ingroup identification is relevant to the individual, cohesion also exists on the group level [33].

In the field of cohesion research, researchers have put an emphasis on attraction (e.g. interpersonal attraction, attraction to the group task, attraction to the group's status). This notion has been criticised as it does not cover everything that binds individuals together to form a group [9]. Henry and colleagues argue that it covers an affective component of binding processes only. Ingroup identification involves affective processes, but cognitive and behavioural processes that lead an individual to identify with a group as well. Although ingroup identification is conceptualised on an individual level, it can generate from different sources which can be on another level (e.g. self-categorization processes or cohesion) [33]. Additional to various sources, the consequences of ingroup identification effect both individual-level and group-level variables. Identification processes are essential for elicitation of group behaviours and enhance among others conformity, cohesion, intergroup competition, stereotyping and discrimination [36].

Another important differentiation can be made concerning duration. Duration is a cue predicting cohesion: the longer a group exists, the more cohesive it gets [26,70]. In the beginning phase of group development, cohesion is nonexistent [70]. This is different with ingroup identification. As known from research of new and unknown groups, an individual's ingroup identification can be high even when joining the group was recent or the group is in the beginning phases of development. Van Veelen and colleagues have described this phenomenon by the self that is projected onto the group [71] [72]. For cohesion, the group (development) comes first, for ingroup identification, the individual and its (conscious or subconscious) decision to identify with the group comes first.

In conclusion, the differentiation between ingroup identification and cohesion is defined by:

- Time of Occurrence: ingroup identification is already present when a group is encountered and cohesion develops within the group over time.

- Level of Existence: ingroup identification happens within the individual (individual-level), but influences and is influenced by group-level characteristics such as cohesion (individual-level and group-level). 
- Dependence on Individual Traits: While cohesion, on the individual level, is conceptualized to mainly depend on an individual's attraction to other members and the task, individual traits play a bigger role in initial ingroup identification processes (the self is projected onto the group).

To our current knowledge, there are no studies on cohesion and ingroup identification in multi-agent groups.

\subsection{Entitativity-Ingroup Identification Relation}

The relationship between entitativity and ingroup identification is embossed by very different understandings and operationalizations of entitativity. In a study on the relationship between entitativity, uncertainty and ingroup identification, entitativity was measured by one question: "How much of a group do you feel they are?". The question was asked to students on a campus who had previously indicated for which political party they voted. They had to think about other people who supported the same party and answer the question thinking about these other people [37]. It is questionable whether one question captures the concept of entitativity. However, the measurement problem lies within mixed perspectives. The student was asked to indicate how much they were a group. Because of the wording they, this measurement can be seen as a perceptual measure from an observer and might count as a measure for entitativity. Still, the student belonged to the same group which was made very salient before when he or she was asked for political orientation. How did they control that the student did not feel part of the group and considered him- or herself when rating the group's groupness (entitativity)? Afterwards, ingroup identification was measured through nine questions adapted from social identity research [37]. Even though the title and hypotheses suggest a study on entitativity and ingroup identification, a closer look into the methods gives a different impression. What did they find? "Ingroup identification was influenced by the interaction of self-uncertainty $[\ldots]$ and perceived political ingroup entitativity" (p. 11, [37]; for a discussion of "ingroup entitativity" cf. also sect. 5.3). According to the current framework, these findings would have to be treated carefully.

Other studies on the relationship between entitativity and ingroup identification rely on the same understanding of the entitativity concept and let ingroup members rate their own ingroup's unity (e.g. [16,17,31,74]. Lickel et al. [53] studied the perception of entitativity from an outsider perspective in two studies and afterwards perception of entitativity from an insider perspective. Although he found the same 4 categories (intimacy groups, social categories, loose associations, task groups), cues such as importance of the group to the self, rather than group-member interaction, was most strongly related to entitativity in the ingroup condition. Duration was stronger positively correlated and permeability was stronger negatively correlated to entitativity. Also, group size was unrelated to entitativity in the ingroup condition, but related in the outside perspective condition [53]. This provides evidence that entitativity from an outsider perspective is differently related to the predictive cues and that belongingness and/ or ingroup identification does play a role in perception of a group. A clear cut between the perspective of research (insider/ member vs. outsider/ observer) as proposed in our framework is very relevant and necessary in order to control for confounding effects of, e.g. ingroup identification, when researching entitativity.

In a study by Castano et al. [17], participants had to rate their ingroup's entitativity (Italian) with items such as 'Italians have many characteristics in common', 'Italians have a sense of common fate' and 'Italy has a real existence as a group'. As in the above described study (political orientation), the group of Italians is a very large group. What becomes apparent is that researchers studying entitativity adapt a more societal perspective and examine rather large collectives instead of small groups. The confounding factor of group belongingness and/ or ingroup identification might not be as highly influential in large collectives as in small groups but is most likely present. What does that mean?

When the relationship between entitativity and ingroup identification is under research and participants belong to the group under study it is very likely that they take themselves into account when rating the group's unity. An observer perspective cannot be occupied by an ingroup member. Castano and colleagues found similar patterns of results for entitativity and ingroup identification in their study and, in consequence, question the discriminant validity of these concepts. They even speculate that the distinction between entitativity and ingroup identification might be artificial [17]. Conducting a factor analysis, they found two underlying factors which indicated that entitativity and ingroup identification are not the same. Still, a clear overlap was found. Entitativity and ingroup identification shared variance in further analyses of data [17]. We argue that this overlap is due to the perspective in measurement level. In the discussed study, the individual level was mixed into the group level of entitativity: ingroup members assessed entitativity (Italians assessed Italian unity). This explains very well why both concepts could not be clearly separated. Again, the importance of perspective and level of measurement is shown.

To conclude, reviews of the concepts of ingroup identification, cohesion and entitativity show considerable overlap in the conceptualization, many cues predicting all three concepts and questionnaires with similar items assessing either one of them. From the 1950s and 1960s, where most research on group dynamics have its roots, the different concepts have spread and been researched by different researchers and branches in sociology and psychology. Small group researchers were mainly occupied with cohesion and 
researchers in the field of large groups concentrated on entitativity. Ingroup identification has been named social identity, group identity and many more. The current framework that puts an emphasis on perspective and level is supposed to serve as a common ground for research in HRI. It can and should be extended to integrate more concepts from groups dynamics research. The framework can provide a theoretical basis for the common understanding of these concepts and a common approach for research.

\section{Methods: Using the I-C-E Framework for HRI Research}

Our review has shown how important it is to (i) know precisely the concept under consideration and (ii) take into account the levels and perspectives when it comes to measuring group phenomena. As discussed in the previous chapter, study results suggest that there is considerable overlap of the concepts entitativity, cohesion, and ingroup identification. However, as we demonstrated, most of this identified overlap can be ascribed to the lack of precise operationalization of the concepts. Hence, it is important to

- decide upon the level of measurement (individual vs. group)

- decide upon the perspective of measurement (insider/ member vs. outsider/ observer)

- decide upon the type of measurement (subjective vs. objective and qualitative vs. quantitative).

\subsection{How to Operationalize Concepts of I-C-E}

Consider the difference between individual- and group-level measurement: Group-level measurements involve questions about and assessments of the group as a whole, individuallevel measurements involve questions addressing the individual.

Consider the difference between outsider/ observer and insider/ member perspective measurement: An outsider or observer assessment requires a person that is not involved in the ingroup, e.g. a participant in an experiment solely observing a group scenario (without being involved in the group). An insider or member perspective requires an ingroup member to rate and evaluate the group.

Consider the difference between subjective and objective measurements: Subjective measurements concern an individual's perception or evaluation, e.g. an observer perceiving the groupness of a group or an ingroup member perceiving the groupness of a group; objective measurements involve structured methodology and do not involve evaluations.

Consider the difference between qualitative and quantitative data: On both levels (individual and group level) and from both perspectives (outsider/ observer and insider/ member), qualitative and quantitative measurements can be used to extract data. Quantitative data result from structured observation and from questionnaires with, for instance, Likert scales. Qualitative data are gathered through interviewing and questionnaires that give option for free-text (e.g. "How do you perceive the group you observed? Write down what you think" for entitativity, "Explain in a few sentences how unified you think your group is." for cohesion and "Do you identify with the group and why? for ingroup identification).

Hohman, Dahl and Grubbs state that "group entitativity is not an objective assessment of cohesiveness but is the perception of the degree of cohesiveness" [38]. In order to measure entitativity, one can ask an observer how cohesive a group appears (group-level variable). Asking an ingroup member exactly the same questions will not result in a measure of entitativity but an ingroup perception of the group's cohesion (group-level variable). The crucial difference between entitativity and cohesion lies in the perceptional perspective.

In Fig. 3, a group consisting of four agents is depicted that is observed by another agent. The picture shows a wellknown social robot (pepper) and a fictitious robot arm. The picture visualizes a scene and will help to differentiate concepts and their level. In the following paragraph, the depicted scene is used to give examples of measurements:

\subsection{How to Measure Entitativity: An Example}

Jonathan walks into a room and sees a group sitting at a table. If we ask Jonathan: "Do the agents around the table look like a group?", he sees two humans and two robots working together. He observes lively interaction and wooden blocks on the table that he infers to be involved in a common task. Group members interact and seem to have different roles. When Jonathan observes the scenario and rates the group's groupness, his rating reflects the group's entitativity. In this case, it is a very subjective perception. In a research setting, entitativity can be measured through independent raters observing interacting group members. For instance, just like Jonathan, raters would be asked to subjectively indicate how entitative the group appears to them. Inter-rater reliability can give an indication on the reliability and objectivity of these ratings. Lickel and colleagues have used a visual analogue scale to report ratings of groups. In order to rank groups according to their entitativity, the measurement is reasonable: it gives a relative measure of entitativity [53]. For absolute measures, is not advised to use. Other researchers have used scales with varying numbers of items rated on Likert scales in order to assess entitativity. As an example, the entitativity cue scale originally included eight items [53] and was extended by one item to also measure cohesion in one study [69]. Clear differences in scales measuring cohesion and entitativity are needed. Additionally, when a scale that is intended to mea- 
Fig. 3 Visualization: a group and its observer
The Group

The Observer
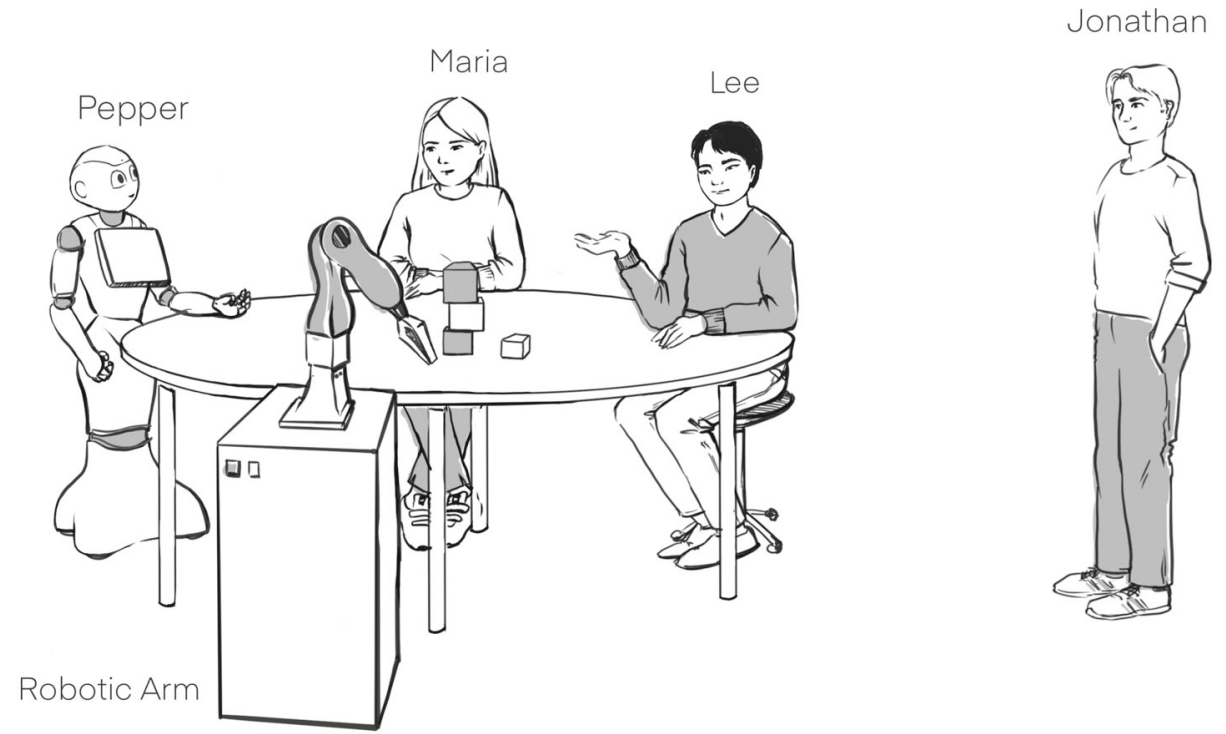

sure entitativity is given to ingroup members, the validity of measurement is at stake. Researchers would have to revise these scales in order to use them to correctly assess entitativity and carefully consider the measurement perspective (outside observer for entitativity).

\subsection{How to Measure Cohesion on a Group-Level: An Example}

Maria sits at a table together with her work group. She has been working with this group for a week. If we ask Maria "Is your work group a real group?", she gives information on her group's status and talks about how well the group works together, that they have the common goal to teach a robot how to grasp objects. After some initial conflicts, she explains, the group has some shared outcomes: the robot arm exhibits some very precise grasping movements. When Maria describes the group progress and the group's dynamics, she describes its cohesion on a group-level. As a group member, Maria has insider information. She can talk about the group's real qualities. Comparing Maria's and Lee's perception of the group can give a broader insight in the group's cohesion on a group-level. Although self-reported data (Maria's and Lee's impression of the group's cohesion) seems the most reasonable for the assessment of cohesion in light of its theoretical definition, observational data can enrich the understanding of a group's cohesion. A very crucial differentiation has to be made in structured, observational measurements and an observer's perception (entitativity). Asking an observer for an evaluation measures entitativity. Observing a group and structuring the observations along well-defined crite- ria can measure cohesion. In order to conduct research with structured observation, well-validated approaches and welltrained researchers are necessary. A possible methodology to study cohesion on a group-level is the interaction process analysis (IPA) by Bales et al. [5]. The method has been used to study small groups and classify interaction into 12 categories belonging to either socio-emotional, relationship oriented interactions or to task oriented interactions. In light of current cohesion research (task and social), these two categories correspond very well and can be used as an observational measure. A subsequent development by Bales et al. [6] is the systematic multiple level observation of groups (SYMLOG) procedure which consists of 26 categories. In order to create a rich understanding of a group's cohesion on a group-level, mixed-methods study designs (objective data, e.g. structured observation including analysis of video data and subjective data through self-report; quantitative and qualitative data) are highly recommended.

\subsection{How to Measure Cohesion on an Individual Level: An Example}

Maria has been working with Pepper, the robotic arm and the newest group member Lee on a research project. If we ask Maria: "Do you belong to the group?", she talks about how much she likes the interaction with the others in the group, especially Pepper, with which she has been working for a while. She feels very dedicated to the common task and has the feeling to be accepted. Here, Maria describes her group's cohesion on an individual-level. In contrast to the study of cohesion on a group-level, the study of cohesion on 
an individual-level can only be conducted by self-report measurements (e.g. questionnaires and interviews). A structured observation can only deliver results on a behavioural level. For an assessment of what Maria feels and thinks about their ingroup, she has to be asked. Even though task and social cohesion are distinct from each other, they are correlated [69]. It is very likely that when Maria feels attracted to the group members (social cohesion), she will be more engaged with the group task (task cohesion). When Maria rates her interpersonal attraction high (individual-level cohesion), she will very likely rate the whole group's unity high (group-level cohesion). For an assessment of a working group's social and task cohesion the GEQ can be used as a measure for cohesion on a group-level and on the individual-level (see above, [15]).

\subsection{How to Measure Ingroup Identification: An Example}

Lee has just joined the research project that Maria has been working on together with Pepper and the robotic arm. If we ask Lee: "How much do you think the group fits to you?, Lee might report the following. When his professor asked him which group he wanted to join, he explicitly named Maria's group. He is a very outgoing person and had seen Maria laugh and have fun while working together with Pepper and the robotic arm. Also, he thinks that the project is very innovative which matches his open-minded and creative character traits. The initial ingroup identification with a multi-agent group can be of great interest to the community of HRI. What does a human lead to identify with such a group? As ingroup identification is likely to evolve [71,72], measuring the concept at the beginning of a developing group, during development and when established will deliver valuable insights. A scale to measure ingroup identification on an individual-level was developed by Arrow and Carini, the Arrow-Carini Group Identification Scale 2.0 [33]. The scale reflects three different facets of ingroup identification: affective (example item: "Members of this group like one another."), behavioral (example item: "This group accomplishes things that no single member could achieve.") and cognitive (example item: "I see myself as quite similar to other members of the group."). A downside of this questionnaire is its mere applicability to existing groups. For groups that have been experimentally sampled, e.g. minimal groups, this questionnaire is not well-fitted. Unfortunately, for recently encountered groups, the questionnaire cannot be used either. Inherent to the definition of ingroup identification in the scale is an interaction component: ingroup identification needs an actively interacting group [33]. In our understanding and concerning more recent research, ingroup interaction can be present before active interaction with a group $[71,72]$. A scale for the initial and new ingroup identification of humans (with a multi-agent group) has to be developed.

\section{Directions and Questions for Future Work}

The field of social robotics and HRI relies on theories from the social sciences. The I-C-E framework provides a common ground for group (dynamics) research in the field, but we see this only as the beginning. Other concepts on group dynamics can be integrated by using the framework's differentiation of group and individual level on the one hand, and the differentiation of inside member or outside observer perspective on the other hand.

The previous chapter has demonstrated that although there are measures available to assess the concepts ingroup identification, cohesion, and entitativity, some of these measures should be revised in order to properly operationalize the concepts they shall cover. This is especially true for entitativity and cohesion. Moreover, further methodological development regarding measures is advisable since we have today other possibilities to technically assist data collection. For instance, eye-contact between interactants might be a relevant but until today rather unexplored measure. With wearable eye-trackers it is possible to explore whether eye-contact between group members relates to low or high ingroup identification or perceived cohesiveness.

With regard to methodology, we further face the task to create meaningful interaction paradigms in HRI to study characteristics of groups and their members. For this purpose, we have to identify which small group paradigms from social psychology research can be transferred and maybe adapted. Also, HRI specific scenarios have to be created, since by their nature, multi-agent groups are different from all-human groups. These differences, especially with regard to (social) capabilities of the robotic group members and hence agency perceptions of the robotic agents in comparison to the human agents are giving research on group dynamics a new twist. This latter overarching question finds its reflection on every concept level as the following potential future research questions will show:

Can a multi-agent group (human-robot group) be entitative? We would postulate that this is the case, as long as predictive cues such as similarity and common goals are somehow apparent to the observer. In accordance with Tennent et al. [68], who built a robotic device, MicBot, that shapes human group interaction, but was not designed to look human-like, future research could focus on the mechanisms that influence observers to perceive entitativity. A robotic team member, like the robotic arm in the drawing, might be used to find the outer borders of entitativity. Would a robotic arm and MicBot be perceived as team members? Or is a robot only perceived as a member if it mimicks the human form and/ or human social behavior?

Can a multi-agent group be cohesive? We would hypothesize that, given group members are attracted to the group itself (social cohesion) and committed to the common 
task (task cohesion), a multi-agent group can be cohesive. The specific circumstances and conditions are to be researched. Fraune et al. [29] have postulated that the cohesion (cohesion according to this framework, although the authors refer to entitativity) can influence the quality of interaction of a human group with a robot.

Can humans identify with robot groups and multiagent groups? The question of ingroup identification with a group of robots might be the most interesting, as it is not yet understood and researched what might lead humans to identify with a robot (group). In contrast to entitativity and cohesion where some research in the field of HRI has been conducted and predictive cues give plausible hypotheses that multi-agent groups can be entitative and cohesive, ingroup identification with robots is still a very open question. The simple prerequisite of red hair as an ingroup identification factor, as in the example above, is not applicable to robots. Being a very novel constellation, a multi-agent group might generally provide the opportunity for more insights in the psychological processes at hand when groups and social identities are formed. As postulated by Reese et al. [61] and their research on identification with all humanity, will the category of humanity stay the highest order of social abstraction? Or will there emerge an even more abstract level of intentional agents with the sub categories humans and robots?

Will these concepts be applicable to physically embodied robots only? The theoretical background from social psychology on relevant concepts for interacting in humanrobot mixed groups generally can also be transferred to other artificially intelligent agents that are virtually embodied or voice-based only as long as these agents are designed to work in groups together with multiple humans. However, prior research has consistently shown that robots and their virtual counterparts can elicit different effects (a review can be found in [52]). In our own prior work, we showed that the embodiment, corporeality and morphology of artificially intelligent systems elicits specific expectations about interaction capabilities of the agents within the human interactants $[34,35]$ which in turn explain differences in the agents' evaluations. Hence, it can be expected that although the concepts and the framework can be used with different kinds of embodiments, the empirical results will probably differ between embodiments thereby providing a different empirical basis to build upon when designing agents for group interactions.

As fascinating as human-robot interaction has been all these years, we look ahead to new and possibly even more interesting times when HRI scholars face countless new research paradigms on (social) group dynamics to be discovered as they boldly go where (almost) no one has gone before.
Acknowledgements Open Access funding provided by Projekt DEAL. The authors would like to thank Laura Platte (Chair Individual and Technology, RWTH Aachen University) for her drawing.

\section{Compliance with Ethical Standards}

Conflict of interest The authors declare that they have no conflict of interest. This is a theoretical paper. Hence, no studies with human subjects were involved.

Ethical guidelines We will follow the national, EU and international ethical guidelines and conventions as laid down in the following documents: the ethical guidelines of the German Psychology Association, the Charter of Fundamental Rights of the EU, Helsinki Declaration in its latest version.

Open Access This article is licensed under a Creative Commons Attribution 4.0 International License, which permits use, sharing, adaptation, distribution and reproduction in any medium or format, as long as you give appropriate credit to the original author(s) and the source, provide a link to the Creative Commons licence, and indicate if changes were made. The images or other third party material in this article are included in the article's Creative Commons licence, unless indicated otherwise in a credit line to the material. If material is not included in the article's Creative Commons licence and your intended use is not permitted by statutory regulation or exceeds the permitted use, you will need to obtain permission directly from the copyright holder. To view a copy of this licence, visit http://creativecomm ons.org/licenses/by/4.0/.

\section{References}

1. Abrams D, Hogg MA (1988) Comments on the motivational status of self-esteem in social identity and intergroup discrimination. Eur J Soc Psychol 18(4):317-334. https://doi.org/10.1002/ejsp. 2420180403

2. Abrams D, Hogg MA, Hinkle S, Otten S (2005) The social identity perspective on small groups. In: Poole MS, Hollingshead AB (eds) Theories of small groups. SAGE, London, pp 99-138. https://doi. org/10.4135/9781483328935.n4

3. Admoni H, Hayes B, Feil-Seifer D, Ullman D, Scassellati B (2013) Are you looking at me? perception of robot attention is mediated by gaze type and group size. In: Staff I (ed) 2013 8th ACM/IEEE international conference on human-robot interaction, IEEE, pp 389-395. [Place of publication not identified]. https://doi.org/10. 1109/HRI.2013.6483614

4. Alves-Oliveira P, Sequeira P, Melo FS, Castellano G, Paiva A (2019) Empathic robot for group learning. ACM Trans Hum Robot Interact 8(1):1-34. https://doi.org/10.1145/3300188

5. Bales RF (1950) Interaction process analysis; a method for the study of small groups. Addison-Wesley, Oxford

6. Bales RF, Cohen SP, Williamson SA (1979) Symlog: a system for the multiple level observation of groups. Free Press, New York

7. Bennewitz M, Faber F, Joho D, Schreiber M, Behnke S (2005) Towards a humanoid museum guide robot that interacts with multiple persons. In: 5th IEEE-RAS international conference on humanoid robots, 2005, IEEE Operations Center, Piscataway, pp 418-423. https://doi.org/10.1109/ICHR.2005.1573603

8. Bollen KA, Hoyle RH (1990) Perceived cohesion: a conceptual and empirical examination. Soc Forces 69(2):479-504. https://doi. org/10.1093/sf/69.2.479

9. Bouas KS, Arrow H (1995) The development of group identity in computer and face-to-face groups with membership change. Com- 
puter Support Coop Work (CSCW) 4(2-3):153-178. https://doi. org/10.1007/BF00749745

10. Breitenstein MD, Reichlin F, Leibe B, Koller-Meier E, van Gool L (2011) Online multiperson tracking-by-detection from a single, uncalibrated camera. IEEE Trans Pattern Anal Mach Intell 33(9):1820-1833. https://doi.org/10.1109/TPAMI.2010.232

11. Burgoon JK, Bacue AE (2003) Nonverbal communication skills. Handbook of communication and social interaction skills, pp 179219

12. Burgoon JK, Buller DB, Hale JL, Turck MA (1984) Relational messages associated with nonverbal behaviors. Hum Commun Res 10(3):351-378. https://doi.org/10.1111/j.1468-2958. 1984.tb00023.x

13. Campbell DT (1958) Common fate, similarity, and other indices of the status of aggregates of persons as social entities. Behav Sci 3(1):14-25. https://doi.org/10.1002/bs.3830030103

14. Carron AV, Brawley LR (2000) Cohesion. Small Group Res 31(1):89-106. https://doi.org/10.1177/104649640003100105

15. Carron AV, Widmeyer WN, Brawley LR (1985) The development of an instrument to assess cohesion in sport teams: the group environment questionnaire. J Sport Psychol 7(3):244-266. https://doi. org/10.1123/jsp.7.3.244

16. Castano E, Yzerbyt V, Bourguignon D (2003) We are one and i like it: the impact of ingroup entitativity on ingroup identification. Eur J Soc Psychol 33(6):735-754. https://doi.org/10.1002/ejsp.175

17. Castano E, Yzerbyt V, Paladino MP, Sacchi S (2002) I belong, therefore, i exist: Ingroup identification, ingroup entitativity, and ingroup bias. Pers Soc Psychol Bull 28(2):135-143. https://doi. org/10.1177/0146167202282001

18. Cattell RB, Saunders DR, Stice GF (1953) The dimensions of syntality in small groups. Hum Relat 6(4):331-356. https://doi.org/10. $1177 / 001872675300600403$

19. Deligianis C, Stanton CJ, McGarty C, Stevens CJ (2017) The impact of intergroup bias on trust and approach behaviour towards a humanoid robot. J Hum Robot Interact 6(3):4. https://doi.org/10. 5898/JHRI.6.3.Deligianis

20. Dion KL (2000) Group cohesion: from "field of forces" to multidimensional construct. Group Dyn Theory Res Pract 4(1):7-26. https://doi.org/10.1037/1089-2699.4.1.7

21. Durkheim E (1947) The division of labor in society. (G.Simpson, Trans.), Free Press, New York, (Original work published 1893)

22. Effron DA, Kakkar H, Knowles ED (2018) Group cohesion benefits individuals who express prejudice, but harms their group. J Exp Soc Psychol 79:239-251. https://doi.org/10.1016/j.jesp.2018.08.002

23. Ellemers N, Haslam SA (2012) Social identity theory. In: van Lange P, Kruglanski A, Higgins E (eds) Handbook of theories of social psychology. SAGE Publications Ltd, London, pp 379-398. https:// doi.org/10.4135/9781446249222.n45

24. Eyssel F, Kuchenbrandt D (2012) Social categorization of social robots: anthropomorphism as a function of robot group membership. Br J Soc Psychol 51(4):724-731. https://doi.org/10.1111/j. 2044-8309.2011.02082.x

25. Festinger L, Schachter S, Back K (1950) Social pressures in informatl groups; a study of human factors in housing. Harper, Oxford

26. Forsyth DR (2014) Group dynamics, 6th edition, student, edition edn. Wadsworth Cengage Learning, Belmont

27. Forsyth DR, Zyzniewski LE, Giammanco CA (2002) Responsibility diffusion in cooperative collectives. Pers Soc Psychol Bull 28(1):54-65. https://doi.org/10.1177/0146167202281005

28. Fraune MR, Nishiwaki Y, Sabanović S, Smith ER, Okada M (2017) Threatening flocks and mindful snowflakes. In: HRI (ed) HRI'17, IEEE, Piscataway, pp 205-213. https://doi.org/10.1145/2909824. 3020248

29. Fraune MR, Šabanović S, Kanda T (2019) Human group presence, group characteristics, and group norms affect human-robot inter- action in naturalistic settings. Front Robot AI 6:3. https://doi.org/ 10.3389/frobt.2019.00048

30. Fraune MR, Sherrin S, Sabanović S, Smith ER (2015) Rabble of robots effects. In: Adams JA, Smart W, Mutlu B, Takayama L (eds) HRI' 15. Associaton for Computing Machinery, New York, pp 109116. https://doi.org/10.1145/2696454.2696483

31. Gaertner L, Schopler J (1998) Perceived ingroup entitativity and intergroup bias: an interconnection of self and others. Eur $\mathbf{J}$ Soc Psychol 28(6):963-980. https://doi.org/10.1002/(SICI)10990992(1998110)28:6<963::AID-EJSP905>3.0.CO;2-S

32. Häring M, Kuchenbrandt D, André E (2014) Would you like to play with me? In: Sagerer G, Imai M, Belpaeme T, Thomaz A (eds) HRI'14. ACM, New York, pp 9-16. https://doi.org/10.1145/ 2559636.2559673

33. Henry KB, Arrow H, Carini B (1999) A tripartite model of group identification. Small Group Res 30(5):558-581. https://doi.org/10. 1177/104649649903000504

34. Hoffmann L, Bock N, Rosenthal-von der Pütten, AM (2019) Not only a matter of embodiment-how morphological differences impact the perception of robot embodiment and corporeality. In: 69th annual meeting of the international communication association. Washington, DC, 2019

35. Hoffmann L, Bock N, v.d. Rosenthal Pütten AM (2018) The peculiarities of robot embodiment (emcorp-scale). In: Kanda T, Ŝabanović S, Hoffman G, Tapus A (eds) HRI'18. Association for Computing Machinery, New York, pp 370-378. https://doi.org/10. $1145 / 3171221.3171242$

36. Hogg MA, Abrams D (1988) Social identifications: a social psychology of intergroup relations and group processes. Taylor \& Frances/Routledge, Florence

37. Hogg MA, Sherman DK, Dierselhuis J, Maitner AT, Moffitt G (2007) Uncertainty, entitativity, and group identification. J Exp Soc Psychol 43(1):135-142. https://doi.org/10.1016/j.jesp.2005. 12.008

38. Hohman ZP, Dahl E, Grubbs S (2016) Entitativity and social identity complexity: the relationship between group characteristics and personal characteristics on group identification. Self Identity 15(6):638-649. https://doi.org/10.1080/15298868.2016.1185462

39. Ip GWM, Chiu CY, Wan C (2006) Birds of a feather and birds flocking together: physical versus behavioral cues may lead to traitversus goal-based group perception. J Pers Soc Psychol 90(3):368381. https://doi.org/10.1037/0022-3514.90.3.368

40. Iqbal T, Rack S, Riek LD (2016) Movement coordination in humanrobot teams: a dynamical systems approach. IEEE Trans Robot 32(4):909-919. https://doi.org/10.1109/TRO.2016.2570240

41. Irfan B, Kennedy J, Lemaignan S, Papadopoulos F, Senft E, Belpaeme T (2018) Social psychology and human-robot interaction. In: Kanda T, Sabanović S, Hoffman G, Tapus A (eds) HRI'18. Association for Computing Machinery, New York, pp 13-20. https://doi. org/10.1145/3173386.3173389

42. Janis I (2008) Groupthink. IEEE Eng Manag Rev 36(1):36. https:// doi.org/10.1109/EMR.2008.4490137

43. Jans L, Leach CW, Garcia RL, Postmes T (2015) The development of group influence on in-group identification: a multilevel approach. Group Process Intergroup Relat 18(2):190-209. https:// doi.org/10.1177/1368430214540757

44. Jung M, Hinds P (2018) Robots in the wild. ACM Trans Hum Robot Interact 7(1): 1-5. https://doi.org/10.1145/3208975

45. Jung MF, Šabanović S, Eyssel F, Fraune M (2017) Robots in groups and teams. In: Lee CP (ed) Companion of the 2017 ACM conference on computer supported cooperative work and social computing. ACM, New York, pp 401-407. https://doi.org/10.1145/ 3022198.3022659

46. Kuchenbrandt D, Eyssel F, Bobinger S, Neufeld M (2011) Minimal group-maximal effect? evaluation and anthropomorphization of the humanoid robot nao. In: Mutlu B, Bartneck C, Ham J, Evers V, 
Kanda T (eds) Social robotics, lecture notes in computer science, vol 7072. Springer, Berlin, pp 104-113. https://doi.org/10.1007/ 978-3-642-25504-5_11

47. Kuchenbrandt D, Eyssel F, Bobinger S, Neufeld M (2013) When a robot's group membership matters. Int J Soc Robot 5(3):409-417. https://doi.org/10.1007/s12369-013-0197-8

48. Kuhn MH, Lewin k (1951) Field theory of social science: selected theoretical papers. (edited by dorwin cartwright.) pp. xx, 346. new york: Harper \& brothers, 1951. \$5.00. Ann Am Acad Political Soc Sci 276(1):146-147. https://doi.org/10.1177/ 000271625127600135

49. Leach CW, van Zomeren M, Zebel S, Vliek MLW, Pennekamp SF, Doosje B, Ouwerkerk JW, Spears R (2008) Group-level selfdefinition and self-investment: a hierarchical (multicomponent) model of in-group identification. J Pers Soc Psychol 95(1):144165. https://doi.org/10.1037/0022-3514.95.1.144

50. Leite I, McCoy M, Ullman D, Salomons N, Scassellati B (2015) Comparing models of disengagement in individual and group interactions. In: Adams JA, Smart W, Mutlu B, Takayama L (eds) HRI' 15. Associaton for Computing Machinery, New York, pp 99105. https://doi.org/10.1145/2696454.2696466

51. Levine JM, Moreland RL (2012) A history of small group research. In: Kruglanski AW, Stroebe W (eds) Handbook of the history of social psychology 2012. Psychology Press, New York, pp 383-405

52. Li J (2015) The benefit of being physically present: a survey of experimental works comparing copresent robots, telepresent robots and virtual agents. Int J Hum Comput Stud 77:23-37. https://doi. org/10.1016/j.ijhcs.2015.01.001

53. Lickel B, Hamilton DL, Wieczorkowska G, Lewis A, Sherman SJ, Uhles AN (2000) Varieties of groups and the perception of group entitativity. J Pers Soc Psychol 78(2):223-246

54. Martelaro N, Jung M, Hinds P (2015) Using robots to moderate team conflict. In: Adams JA (ed) Proceedings of the tenth annual ACMIEEE international conference on human-robot interaction extended abstracts. ACM, New York, p 271. https://doi.org/10. 1145/2701973.2702094

55. McFarland S, Webb M, Brown D (2012) All humanity is my ingroup: a measure and studies of identification with all humanity. J Pers Soc Psychol 103(5):830-853. https://doi.org/10.1037/ a0028724

56. McGarty C, Haslam SA, Hutchinson KJ, Grace DM (1995) Determinants of perceived consistency: the relationship between group entitativity and the meaningfulness of categories. $\mathrm{Br} \mathrm{J}$ Soc Psychol 34(3):237-256. https://doi.org/10.1111/j.2044-8309. 1995.tb01061.x

57. Mitzel D, Leibe B (2012) Taking mobile multi-object tracking to the next level: people, unknown objects, and carried items. In: Hutchison D, Kanade T, Kittler J, Kleinberg JM, Mattern F, Mitchell JC, Naor M, Nierstrasz O, Pandu Rangan C, Steffen B, Sudan M, Terzopoulos D, Tygar D, Vardi MY, Weikum G, Fitzgibbon A, Lazebnik S, Perona P, Sato Y, Schmid C (eds) Computer vision-ECCV 2012, lecture notes in computer science, vol 7576. Springer, Berlin, pp 566-579. https://doi.org/10.1007/978-3-64233715-4_41

58. Mullen B, Copper C (1994) The relation between group cohesiveness and performance: an integration. Psychol Bull 115(2):210227

59. Osep A, Mehner W, Voigtlaender P, Leibe B, (2018) Track, then decide: category-agnostic vision-based multi-object tracking. In: Lynch K, I.I.C.o.R.a. Automation (eds) (2018) IEEE international conference on robotics and automation (ICRA). IEEE, Piscataway, pp 3494-3501. https://doi.org/10.1109/ICRA.2018.8460975

60. Peralta CF, Lourenço PR, Lopes PN, Baptista C, Pais L (2018) Team development: definition, measurement and relationships with team effectiveness. Hum Perform 31(2):97-124. https://doi.org/10. 1080/08959285.2018.1455685
61. Reese G, Proch J, Finn C (2015) Identification with all humanity: the role of self-definition and self-investment. Eur J Soc Psychol 45(4):426-440. https://doi.org/10.1002/ejsp.2102

62. Richter V, Carlmeyer B, Lier F, Meyer zu Borgsen S, Schlangen D, Kummert F, Wachsmuth S, Wrede B (2016) Are you talking to me? In: Yau WY, Omori T, Metta G, Osawa H, Zhao S (eds) HAI'16. The Association for Computing Machinery, New York, pp 43-50. https://doi.org/10.1145/2974804.2974823

63. Rutchick AM, Hamilton DL, Sack JD (2008) Antecedents of entitativity in categorically and dynamically construed groups. Eur J Soc Psychol 38(6):905-921. https://doi.org/10.1002/ejsp.555

64. Sabanovic S, Michalowski MP, Simmons R (2016) Robots in the wild: observing human-robot social interaction outside the lab. In: The 9th IEEE international workshop on advanced motion control. IEEE, Piscataway, pp 596-601. https://doi.org/10.1109/AMC. 2006.1631758

65. Shen S, Slovak P, Jung MF (2018) Stop. I see a conflict happening. In: Kanda T, Ŝabanović S, Hoffman G, Tapus A (eds) HRI'18. ACM, New York, pp 69-77. https://doi.org/10.1145/ 3171221.3171248

66. Simmel G (1902) The number of members as determining the sociological form of the group. ii. Am J Sociol 8(2):158-196

67. Tajfel H, Billig MG, Bundy RP, Flament C (1971) Social categorization and intergroup behaviour. Eur J Soc Psychol 1(2):149-178. https://doi.org/10.1002/ejsp.2420010202

68. Tennent H, Shen S, Jung M (2019) Micbot: a peripheral robotic object to shape conversational dynamics and team performance. In: 2019 14th ACM/IEEE international conference on human-robot interaction (HRI). IEEE (3/11/2019 - 3/14/2019), pp 133-142. https://doi.org/10.1109/HRI.2019.8673013

69. Thurston JA (2012) Exploring group perception: the relationship between the perception of entitativity and assessments of cohesion. University of California, Santa Barbara

70. Tuckman BW, Jensen MAC (1977) Stages of small-group development revisited. Group Organ Stud 2(4):419-427. https://doi.org/ $10.1177 / 105960117700200404$

71. van Veelen R, Otten S, Hansen N (2013) A personal touch to diversity: self-anchoring increases minority members' identification in a diverse group. Group Process Intergroup Relat 16(6):671-683. https://doi.org/10.1177/1368430212473167

72. van Veelen R, Otten S, Hansen N (2013) Social identification when an in-group identity is unclear: the role of self-anchoring and selfstereotyping. Br J Soc Psychol 52(3):543-562. https://doi.org/10. 1111/j.2044-8309.2012.02110.x

73. Weiss A (2012) HRI research. In: Yanco H (ed) Proceedings of of the seventh annual ACMIEEE international conference on humanrobot Interaction, ACM Digital Library. ACM, New York, p 271. https://doi.org/10.1145/2157689.2157789

74. Yzerbyt V, Castano E, Leyens JP, Paladino MP (2000) The primacy of the ingroup: the interplay of entitativity and identification. Eur Rev Soc Psychol 11(1):257-295. https://doi.org/10. 1080/14792772043000059

75. Zaraki A, Mazzei D, Giuliani M, de Rossi D (2014) Designing and evaluating a social gaze-control system for a humanoid robot. IEEE Trans Hum Mach Syst 44(2):157-168. https://doi.org/10. 1109/THMS.2014.2303083

Publisher's Note Springer Nature remains neutral with regard to jurisdictional claims in published maps and institutional affiliations. 